\title{
Peran Caregiver dalam Pemberian Metode Visual Support pada Individu ASD
}

\author{
HANUN NURFADIYAH \& TRI KURNIATI AMBARINI*
}

Departemen Psikologi Klinis dan Kesehatan Mental Fakultas Psikologi Universitas Airlangga

\begin{abstract}
ABSTRAK
Penelitian ini bertujuan untuk memberikan gambaran peran yang dilakukan oleh caregiver dalam pemberian metode dukungan visual pada individu autis. Individu autis memiliki hambatan perkembangan seperti komunikasi dan menerima informasi, namun memiliki otak visual yang baik, untuk itu dukungan visual dapat dijadikan metode yang efektif untuk menterjemahkan informasi menjadi bentuk visual. Keberhasilan metode ini tidak terlepas dari keterlibatan caregiver dalam menyampaikannya. Penelitian ini menggunakan pendekatan kualitatif tipe studi kasus, dengan subjek dua orang tua sekaligus sebagai caregiver. Teknik pengumpulan data menggunakan wawancara semiterstruktur. Teknik analisis data yang digunakan adalah analisis data tematik data driven. Hasil penelitian menunjukkan bahwa terdapat tujuh peran yang dilakukan oleh caregiver, yaitu pengajar, pengawas, pembimbing, pelajar, penyedia, penyesuai, dan perpanjangan tangan terapis. Faktor pendukung yang ditemukan adalah informasi yang dimiliki tentang autisme dan dukungan visual, dukungan sosial, dan pengalaman. Faktor penghambat yaitu cara untuk menyederhanakan informasi, ketidakpastian efektivitas penyampaian informasi, dan menyesuaikan topik informasi menjadi bentuk visual.
\end{abstract}

Kata kunci: autisme, peran caregiver, visual support

\begin{abstract}
This study is conducted to provide an overview of the roles taken by the caregiver in providing visual support for autistic individuals. Autistic individuals have several developmental barriers as in communication and understanding information, but they have better visual thinking ability, therefore visual support could be an effective method to translate information into images. The success of this method can't be separated from the caregiver involvement in delivering it. This study uses qualitative approach with two parents who also caregivers as subjects. Data was gathered with semi-structured interview, analyzed with thematic-analysis technique. Results shows there are seven roles, namely as teachers, supervisors, mentors, students, providers, adapters, and therapist's extension. Supporting factors are the amounts of information they have about autism and visual support, social support, and experiences. The inhibiting factors are how to simplify the information, and uncertainty about the effectiveness of delivering, also adjusting the information into visual form.
\end{abstract}

Keywords: autism, caregiver roles, visual support 
Naskah ini merupakan naskah dengan akses terbuka dibawah ketentuan the Creative Common Attribution License (CC-BY-4.0) (http://creativecommons.org/licenses/by/4.0), sehingga penggunaan, distribusi, reproduksi dalam media apapun atas artikel ini tidak dibatasi, selama sumber aslinya disitir dengan baik.

\section{P E N D A H U L U A N}

Gangguan spektrum autistik (GSA) atau autistic spectrum disorder (ASD) merupakan gangguan perkembangan yang dapat terlihat pada dua tahun pertama dalam kehidupan anak atau pada usia 1224 bulan (American Psychiatric Association, 2013). Dalam beberapa kasus gejala autsime muncul pada usia 2 tahun sedangkan dalam kasus lain gejala muncul lebih lama dan diagnosa formal diterima ketika anak berusia 4-5 tahun atau lebih tua. Setiap anak memiliki gejala berbeda, tidak sama dengan anak lain, terdapat kekhususan dalam masing-masing anak. Gejala dapat bervariasi dari ringan hingga berat, gangguan utama yang dialami oleh anak dengan autisme yang paling terlihat adalah kesulitannya dalam berkomunikasi atau berinteraksi dengan orang lain (Iowa Departement of education early childhood services beurau, 2010).

American Psychiatric Association (APA) mengklasifikasikan ASD dalam neurodevelopmental disorder dimana terdapat lima kriteria diagnostik untuk $A S D$ dalam DSM-V dengan tiga ciri utama yaitu, gangguan pada komunikasi, interaksi sosial, dan keterbatasan minat serta kemampuan imajinatif (Ginanjar, 2007). Pada gangguan komunikasi Tager-Flusberg (2003) mengidentifikasikan kemampuan anak dengan autisme menjadi 2 yaitu anak autisme dengan kemampuan linguistik yang normal dan anak autisme dengan kemampuan linguistik menyerupai gangguan bahasa.

Individu $A S D$ dapat dibantu dengan menggunakan bebrapa intervensi yang tujuannya adalah untuk membangun kemampuan komunikasi, beberapa diantaranya adalah dengan menggunakan metode visual support atau dukungan visual, terapi okupasi, terapi wicara, dan lain-lain. Individu $A S D$ sendiri memiliki kemampuan visual thinking yang lebih baik, mereka lebih mudah dalam memahami hal-hal konkrit daripada abstrak (Ratri, 2016). Individu ASD umumnya lebih menggunakan proses berpikir asosiasi daripada logika, proses berpikir seperti ini kadang membuat anak membutuhkan waktu sedikit lebih lama untuk memproduksi kata dan melakukan sesuatu (Ratri, 2016).

Grandin (1995) dan Kunda \& Goel (2011) menemukan bahwa individu dengan ASD yang menggunakan dukungan visual memiliki fungsi perseptual yang lebih tinggi, ini karena kemampuan citra mental atau "visual thinking" mereka jauh lebih tinggi ketika terlibat dalam pemrosesan visual jika dibandingkan dengan individu dengan kemampuan perkembangan tipikal. Individu dengan $A S D$ cenderung memproses penalaran dan pemecahan masalah melalui serangkaian proses imajeri daripada menggunakan kata-kata (Grandin (1995); Kunda \& Goel (2011) dalam Hume, dkk., (2014)). Dengan adanya dukungan visual penyandang $A S D$ menjadi lebih mudah dalam menerima informasi, meskipun dukungan visual menyajikan materi yang cenderung bersifat global namun infomasi yang diberikan cukup detail sehingga memungkinkan bagi penyandang $A S D$ untuk lebih mudah memahaminya (Hume, dkk., 2014).

Dukungan visual beruapa jadwal dan skema dapat membantu individu $A S D$ dalam menyelesaikan halhal yang berkaitan dengan fungsi eksekutif. Fungsi eksekutif merupakan istilah yang digunakan untuk menjelaskan proses otak dalam megambil keuputusan dan menyimpan infromasi saat menerima stimulus (McLeod, 2012). Penelitian Hill (2004) menunjukkan bahwa penyandang ASD memiliki kesulitan dalam bidang perencanaan dan pengambilan keputusan, kedua hal tersebut berkaitan dengan

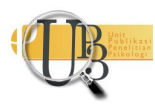


kemampuan memproses bahasa dan pemrosesan informasi yang mana menjadi kekurangan pada penyandang $A S D$ ( (Hill, 2004) dalam (Hume, dkk., 2014)).

Dukungan visual memiliki banyak manfaat dan tantangan tersendiri saat digunakan, Hayes (2010) menjelaskan ada 3 masalah yaitu, bagaimana alat yang digunakan harus dapat membantu individu yang menggunakannya, keluwesan alat yang digunakan, dan kendala yang dihadapi oleh caregiver. Istilah caregiver mempunyai banyak definisi, Hunt (2003) menjelaskan istilah ini sebagai individu yang memberikan perawatan pada orang atau pasien yang membutuhkan tanpa dibayar. Apabila diterjemahkan secara harfiah, caregiver berarti pengasuh, menurut Kamus Besar Bahasa Indonesia pengasuh berarti orang yang mengasuh atau wali (KBBI).

Caregiver umumnya memiliki kesulitan saat membuat, menggunakan, dan mengontrol efektivitas penggunaan dukungan visual (Meadan, dkk., 2011). Tantangan yang sering dihadapi yaitu caregiver harus memiliki infomasi yang cukup kemudian memilih metode yang tepat untuk digunakan dalam satu setting tertentu. Menjadi tugas caregiver untuk memilih dan mengevaluasi apakah metode dukungan visual yang digunakan telah sesuai dan efektif. Memperbarui media yang digunakan juga menjadi tugas dari caregiver agar alat bantu visual selaras dengan perkembangan dan kebutuhan individu. Untuk melakukan hal ini caregiver harus mengetahui kendala yang dialami individu dan target yang ingin dicapai sambil meminimalisir beban yang ditangunggnya (Hayes dkk, 2010).

Individu autis memiliki penggunaan bahasa yang tidak biasa, apabila individu yang merawat tidak terbiasa atau pertama kali berada di sekitar anak akan mengalami kesulitan dalam menginterpretasi apa yang ingin disampaikan oleh anak (Tager-Flusberg dkk., 2019). Sinkronisasi orang tua dengan anak juga merupakan sebuah faktor yang juga tidak dapat dilepaskan sebagai seorang caregiver, pemahaman caregiver terhadap perhatian dan aktivitas anaknya dapat membuat perkembangan anaknya menjadi lebih optimal, Siller dan Sigman (2002) menemukan bahwa apabila caregiver mampu menyinkronkan dirinya dengan anaknya dalam level yang tinggi maka kemampuan anaknya dalam berbahasa juga akan meningkat dengan pesat.

Dyrbjerg dan Vedel menjabarkan bagaimana faktor keterlibatan caregiver, dalam kasus ini yaitu orang tua, diperlukan setiap saat. Batuan visual yang digunakan haruslah cukup mendetail dan spesifik sehingga dapat digunakan secara efekfit, untuk mencapai detail dan spesifikasi yang diinginkan maka caregiver perlu terlibat secara dalam dengan seagala kegiatan anak (Dyrbjerg \& Vedel, 2007). Dyrbjerg dan Vedel (2007) juga menjelaskan bagaimana caregiver harus membuat banyak dukungan visual seperti jadwal visual, kartu visual, dan metode lain untuk mencakup seluruh kegiatan anak mulai bangun tidur, mandi, makan, bermain dengan anak lain, berbagi mainan, dan kegiatan lainnya.

Orang tua yang menjadi caregiver dapat disebut sebagai family caregiver atau informal caregiver, berbeda dengan staff formal yang dibayar untuk memantau kondisi medis pasien tugas informal caregiver lebih beragam, salah satunya adalah untuk membantu staff formal mengetahui kondisi pasien dengan lebih dalam termasuk respon orang yang dirawat terhadap suatu intervensi, situasi, dan aktivitas tertentu (Milligan, 2005). Staff formal dapat menyediakan saran ahli sesuai dengan keterampulannya, sedangkan family caregiver dapat memberikan insight mengenai kondisi individu yang dirawat terkait dengan kondisi sosial, budaya, latar belakang, dan hal penting lain yang sekiranya perlu diketahui oleh staff formal (Milligan, 2005). Dengan kedua pihak berkolaborasi atas pengetahuannya masing-masing dapat meningkatkan kualitas perawatan yang diterima oleh individu dalam perawatan. 
Salah satu perhatian utama pada penyandang $A S D$ adalah kemampuan berkomunikasinya dengan orang lain, apabila komunikasi tidak terbangun dengan baik maka informasi akan sulit untuk dicerna, terdapat beberapa intervensi yang dapat digunakan untuk mempermudah anak dalam membangun komunikasi, salah satunya dengan menggunakan metode visual support. Metode yang dijelaskan pada dasarnya menggunakan alat bantu visual seperti gambar, foto, video, dan bahasa tubuh untuk membantu anak dalam memahami perintah, perkataan, dan rutinitas. Meskipun dinilai sebagai metode yang efektif dan cenderung mudah diterapkan namun kesuksesan metode ini tetap tergantung pada pengetahuan dan kemampuan tenaga pengajar atau caregiver. Berdasarkan latar belakang permasalahan yang telah dijelaskan di atas, penulis ingin mengetahui apa saja peran caregiver dalam pemberian vsiual support bagi individu dengan $A S D$.

Penulis melakukan literature review pada penelitian Dettmer dkk. (2000), Johnston dkk. (2003), dan Koesdiningsih (2018), penulis menemukan bahwa ketiga penelitian tersebut lebih berfokus pada efektivitas penggunaan metode visual support, sedangkan penelitian yang berfokus pada peran caregiver dalam penyampaian metode tersebut belum banyak diteliti, untuk itu penulis tertarik mencari tahu mengaai peran caregiver dalam pemberian bantuan visual. Penelitian ini bertujuan untuk mencari tahu secara empiris peran caregiver dalam pemberian metode dukungan visual pada individu ASD dalam kehidupan sehari-hari.

\section{E T O D E}

\section{Desain Penelitian}

Tipe penelitian mengenai peran caregiver dalam pemberian metode visual support pada individu $A S D$ adalah jenis penelitian kualitatif jenis studi kasus. Penulis memilih menggunakan metode kualitatif dipertimbangkan dari latar belakang penelitian serta tujuan penelitian untuk mengungkapkan kejadian di setting sesungguhnya tanpa tujan untuk menggeneralisasikan suatu fenomena.

\section{Partisipan}

Pemilihan subjek dilakukan dengan teknik sampling yang khas dari penelitian kualitatif yaitu teknik non-probability sampling jenis purposive sampling. Partisipan dalam penelitian ini adalah caregiver dari individu dengan autism spectrum disorder yang menggunakan alat bantu visual, caregiver yang dicari adalah mereka yang juga turut berperan dalam membantu individu menggunakannya, caregiver juga turut berpartisipasi dalam membuat, menyusun, dan menyesuaikan alat bantu visual yang digunakan. Partisipan dipilih yang tinggal di Surabaya berdasarkan jangkauan penulis, penulis tidak membatasi pemilihan pada usia, jenis kelamin, suku, ras, atau status ekonomi tertentu. Kriteria lainnya partisipan secara sukarela bersedia berpartisipasi dalam penelitian ini sesuai dengan lembar informed consent, pada akhirnya penulis menggunakan 2 orang partisipan dalam penelitian ini.

\section{Strategi Pengumpulan Data}

Teknik penggalian data utama dalam penelitian ini adalah wawancara mendalam (in-depth interview) sesuai pedoman atau blueprint wawancara. Penulis hanya membuat beberapa pertanyaan pada pedoman wawancara, pertanyaan lainnya dikembangkan sesuai dengan jawaban dari partisipan. Wawancara yang penulis lakukan adalah wawancara secara langsung dengan bertemu partisipan dan dengan melakukan videocall. Teknik kredibilitas yang penulis gunakan adalah dengan member check dimana data yang penulis interpretasikan diperlihatkan kepada partisipan untuk diperiksa kebenarannya. 


\section{Analisis Data}

Analisis data yang digunakan dalam penelitian ini adalah analisis tematik seperti yang dijelaskan oleh Braun \& Clarke (2006). Analisis tematik ini bertujuan untuk memahami fenomena atau gejala sosial dengan lebih menitik beratkan pada gambaran yang lengkap tentang fenomena yang dikaji dari pada merincinya menjadi variabel-variabel yang saling terkait. Langkah awal yang dilakukan adalah mengenali data, data yang telah dijabarkan kemudian diberi koding seuai dengan pola yang muncul. Setelah melukan koding kemudian data dikelompokkan dan dinaikan menjadi tema. Tema yang muncuk inilah yang kemudian dijadikan acuan dalam membuat laporan.

\section{HAS I L P EN EL I T I A N}

\section{Hasil temuan subjek 1}

Subjek 1 berinisial RH merupakan seorang ibu sekaligus caregiver dari anak autis berusia 7 tahun. Subjek merupakan lulusan S1 dan merupakan seorang ibu rumah tangga. dalam keterlibatannya dalam pemberian metode dukungan visual RH memiliki 6 peran yaitu:

Sebagai pelajar, bukan hanya menjadi pengajar namun subjek juga menjadi pelajar untuk mempelajari mengenai bagaimana autisme, apa itu visual support, dan bagaimana keduanya sangat bergantung antara satu sama lain. Subjek cukup mengetahui tentang bagaimana pola pikir individu autis, subjek juga cukup mengerti bahwa dalam pemakaian dukungan visual tidak perlu banyak kata yang digunakan.

Sebagai Pengajar, subjek mengajarkan anaknya berbagai keilmuwan seperti berhitung, membaca, pengetahuan umum, dan Bahasa Inggris. Subjek juga mengajarkan konsentrasi, keteraturan, kegiatan sehari-hari dan membangun kebiasaan baik, Dalam prakteknya subjek menggunakan buku ensiklopedi, gambar, dan mainan edukasi. Subjek mengajarkan anaknya bagaimana cara mandi sendiri, cara membereskan mainan, dan untuk membuang sampah pada tempatnya dengan menunjukkan pada subjek gambar melakukan kegiatan tersebut langkah demi langkah.

Melanjutkan peran guru dan terapis, subjek mempelajari dukungan visual dari guru dan terapis, otomatis peran guru dan terapis akan berlanjut di rumah. Subjek melanjutkan mendidik anaknya menggunakan kolase, puzzle, dan mainan edukasi seperti yang dilakukan terapisnya sambil sesekali berkonsultasi. Sedangkan untuk di TK, umumnya guru menyuruh muridnya untuk membawa pulang media visual yang digunakan dan dipelajari di rumah.

Sebagai penyedia, subjek bertanggung jawab atas ada atau tidaknya media dukungan visual yang ada di rumah. Tergantung kebutuhan, umumnya subjek menyediakan alat bantu visual dengan membuatnya atau membelinya. Sejauh ini subjek lebih banyak membeli media visual dalam bentuk buku, puzzle, dan mainan edukasi. Subjek kebanyakan membuat untuk mengajarkan kegiatan sehari-hari dan untuk menjelaskan tempat baru saat akan berwisata.

Sebagai pengawas, Subjek selalu memperhatikan tumbuh kembang anaknya dan senantiasa menyesuaikan diri dengam kebutuhannya. Subjek mengetahui apabila ada perubahan pada diri anaknya, serta mengetahu bagaimana kebiasaan anaknya. Peran subjek adalah sebagai pengawas untuk mengawasi setiap hal yang terjadi pada diri anaknya. Pengajaran yang subjek berikan bergantung pada kebutuhan dan perubahan yang mungkin saja terjadi.

Sebagai pembimbing, Melalui dukungan visual subjek dapat melakukan kontrol perilaku dimana subjek akan menjelaskan perilaku seperti apa yang subjek harpapkan dari anaknya. Ini sekaligus 
mengajari anaknya bahwa ada perilaku yang diharapkan seperti buang sampah pada tempatnya, mandi sendiri, atau membereskan mainan sendiri dan ada perilaku yang tidak seharusnya dilakukan seperti main HP terlalu lama dan tidak mau sekolah.

\section{Hasil temuan subjek 2}

Subjek 2 berinisial AS merupakan seorang ayah dari anak autis berusia 19 tahun, subjek merupakan lulusan S3 dan sehari-hari bekerja sebagai seorang pustakawan. Subjek telah menggunakan dukungan visual sejak anaknya masih SD, semakin dewasa anaknya semakin sedikit subjek menggunakan dukungan visual dan lebih banyak mencotohkan secara langsung. Dalam penggunaan dukungan visual sehari-hari subjek memiliki 6 peran yaitu:

Sebagai pelajar, AS melakukan riset yang cukup dalam mengenai autisme dan dukungan visual. AS mempelajari autisme dari dokter dan psikolog yang kemudian menuntun AS untuk melakukan riset mengenai dukungan visual dengan membaca banyak jurnal. AS memahami fungsi otak individu autis bekerja lebih baik dengan cara visual untuk itu ia mendedikasikan dirinya mempelajari strategi visual agar dapat merawat anaknya sendiri, subjek mempelajari bagaimana dukungan visual bekerja, dan bagaimana untuk mengaplikasikannya dalam kehidupan sehari-hari.

Sebagai pengajar. AS mengajarkan banyak hal pada anaknya melalui strategi visual, diantaranya adalah pelajaran formal seperti Bahasa Inggris dan IPA. menggunakan gambar untuk setiap kata yang dipelajari dan menggunakan story board untuk menjelaskan tentang perubahan jenis benda. AS merasa bahwa ia tidak terlalu banyak mengajarkan keilmuwan, AS lebih mengajarkan anaknya bagaimana untuk bertahan hidup secara mandiri. AS mengajarkan bagaimana agar anaknya dapat mencuci, sholat, merawat diri, serta menjaga kebersihan secara umum. Dalam proses pembelajaran ini AS sekaligus membentuk rutinitas agar anaknya disiplin.

Sebagai penyedia, pada tahun-tahun pertama perkembangan, AS lebih sering membelikan mainan edukasi seperti puzzle untuk anaknya namun semakin bertembah usia kebutuhan juga ikut berubah untuk itu AS lebih banyak membuat sendiri atau memodifikasi barang yang ada di rumah untuk pembelajaran anaknya. AS membuat banyak media pengajaran seperti foto, gambar, story board, dan video. AS paham bahwa kemampuan duplikasi anaknya sangat tinggi untuk itu semakin dewasa AS lebih suka mencontohkan apa yang harus dilakukan daripada menggunakan gambar. Anak AS memiliki kemampuan visual yang tinggi maka dari itu hanya dengan melihat AS ia sudah bisa menirukan.

Sebagai pembimbing, AS mengerti bahwa ia tidak dapat selalu memgontrol apa yang anaknya lihat oleh karena itu AS melakukan tindak pencegahan dengan mengajarkan konsekuensi serta perilaku yang baiknya dilakukan. AS melakukan ini dengan cara menunjukkan akibatnya apabila orang bertindak kriminal yaitu dipenjara. AS juga sering mengajak anaknya untuk mengaji dan beribadah agar tidak melakukan tindakan yang aneh. Peran pembimbing tidak berhenti sampai disini, AS juga merasa harus membekali anaknya dengan ilmu yang bermanfaat agar kelak ia bisa mandiri, untuk itu AS mengajarkan anaknya menggunakan komputer dengan harapan ia akan mendapatkan pekerjaan yang bagus. AS juga mengajari anaknya untuk mencintai pendidikan dan mencintai pekerjaannya sebagai pustakawan, ini dilakukan dengan menunjukkan foto dan video. Tujuan AS adalah agar anaknya termotivasi mengenyam pendidikan tinggi dan mencari pekerjaan yang baik.

Sebagai pengawas, AS senantiasa mengawasi perkembangan yang dialami anaknya, dimana anaknya butuh sesuatu maka AS akan mencoba untuk memenuhinya. Tentu saja hal ini tidak mudah, AS harus memahami kebiasaan anaknya, dimana saat AS bisa masuk untuk mengajari dan dimana ia tidak bisa 
diganggu. Selama ini AS menunggu saat anaknya tenang sebelum mengajari sesuatu, atau menggunakan kesukaan anaknya sebagai penarik perhatian agar mau mendengarkan. Kondisi anaknya juga sebagai pertimbangan, semisal saat ini anaknya sedang megalami pubertas maka AS akan mejelaskannya atau saat anaknya terlalu banyak main game AS juga harus menerangkan konsekuensinya.

Menyesuaikan dengan individu autis, Anak AS memiliki kemampuan duplikat yang bagus untuk itu AS tidak boleh menunjukkan perilaku atau etikat buruk didepannya. AS selalu berusaha untuk menjaga sikap, gaya bicara, dan berperilaku sopan dihadapan anaknya. Subjek menjelaskan bahwa perilaku buruk lebih mudah terekam di otak daripada yang baik untuk itu ia ingin meminimalisir paparan perilaku buruk dihapannya. Penyesuaian tidak hanya terbatas pada perilaku namun juga pada metode visual yang digunakan, AS menyadari bahwa ada beberapa gambar dan media yang tidak dapat digunakan untuk mengajari anaknya untuk itu memilih media yang sesuai sangat penting demi tersampaikannya informasi. AS mampu mengajarkan banyak hal namun ada juga yang AS tidak bisa ajarkan salah satunya adalah berteman, AS telah menggunakan dukungan visual namun memang anaknya yang tidak mau membangun hubungan pertemanan, hal ini cukup AS sayangkan.

\section{I S K U S I}

Peran AS dan RH sama-sama bertujuan untuk menerjemahkan informasi dari verbal menjadi bentuk visual sesuai dengan kebutuhan anak mereka. Dalam prosesnya AS mencakup lebih banyak peran jika dibandingkan dengan RH. Hal ini karena level pemahaman yang berbeda, AS melakukan riset lebih dalam sehingga mendapatkan informasi yang lebih banyak daripada RH maka dari itu jangkauan penggunaan dukungan visualnya berbeda. Ini sejalan dengan teori Hayes (2010)yang menyatakan bahwa kecukupan informasi mempengaruhi penggunaan dan efektivitas metode dukungan visual. Sumber informasi RH umumnya dari guru maupun terapis yang kemudian diadaptasi untuk dipakai sendiri, sedangkan AS memiliki lebih banyak sumber informasi yang ia kolaborasikan. Sumber informasi AS adalah jurnal, buku, sumber bacaan lain, dari dokter, dan dari psikolog.

Subjek RH dan AS merupakan orang tua yang menjadi caregiver untuk anaknya maka dari itu RH dan AS disebut sebagai family caregiver, tugas yang dibebankan pada keduanya tidak hanya sebatas merawat kebutuhan sehari-hari anaknya namun juga memantau kondisi medis, kebutuhan perkembangan, dan kontrol dalam penggunaan metode dukungan visual. Milligan (2005)memaparkan sejumlah tugas family caregiver yaitu memenuhi kebutuhan dasar, membantu perawatan sosial, perawatan emosional, dan memantau kondisi.

Dyrbjerg dan Vedel (2007) menyatakan dalam penelitiannya bahwa caregiver perlu terlibat dengan segala kegiatan anak dan membuat banyak dukungan visual untuk digunakan. RH dan AS sendiri dapat dikatakan banyak terlibat dalam kehidupan anaknya. Kedua subjek harus selalu mengikuti tumbuh kembang anaknya, memperhatikan apa yang mereka butuhkan dan melakukan tindakan sesuai dengan yang diperlukan. Selama ini RH lebih banyak menyediakan dukungan visual dengan cara membeli, ini karena anak RH yang masih berusia 7 tahun jadi mainan edukatif masih besar perannya. Hanya jika ada situasi khusus baru RH membuat media visual. Sedangkan untuk AS yang anaknya sudah dewasa ia lebih banyak membuat dukungan visual dan mecontohkan. AS menyatakan bahwa mencontohkan juga sama efektifnya dengan menggunakan gambar.

Faktor yang mempengaruhi keberhasilan ke dua subjek adalah karena adanya informasi dan edukasi yang mereka terima baik tentang metode dukungan visual maupun mengenai autisme. Selain itu faktor dukungan dari orang lain juga berpengaruh, RH mendapatkan tuntunan dari guru dan terapis anaknya, 
sedangkan AS mendapatkan informasi dari dokter dan psikolog. Adanya pengalaman dalam membuat dan menggunakan juga tidak kalah penting, semakin sering caregiver membuat maka caregiver akan semakin mahir dan percaya diri dalam menyampaikan. Faktor penghambat dalam pemberian metode dukungan visual, yaitu bagaimana untuk membuat dan menyampaikan media visual dengan tepat. Menurut pernyataan AS, ia kadang kesulitan untuk menyesuaikan topik yang ingin diajarkan dengan media untuk pengajaran. Selain itu RH juga menceritakan kesulitannya untuk menyederhanakan informasi agar dapat tersampaikan dengan menggunakan metode visual, RH juga tidak yakin apakah informasi yang ia berikan tersampaikan atau tidak.

\section{S I M P U L A N}

Hasil penelitian ini memaparkan mengenai peran yang dijalankan oleh caregiver dalam pemberian visual support pada individu $A S D$ peran yang ditemukan antara lain yaitu sebagai pelajar, penyedia, pengajar, pembimbing, pengawas, melanjutkan peran terapis dan guru, juga peran dalam menyesuaikan dengan individu autis. Sedangkan peran utama adalah bagaimana caregiver menterjemahkan infomasi yang tersedia menjadi bentuk visual.

Saran untuk penggunaan dukungan visual bagi anak autis usahakan mengetahui anak sebaik mungkin agar penggunaan dukungan visual dapat disesuaikan dengan baik tergantung kebutuhan anak. Ada media tertentu yang mungkin tidak efektif untuk digunakan untuk itu penting bagi caregiver agar mengetahui media atau gambar seperti apa yang memberikan efek paling besar saat digunakan. Semakin banyak membuat dan menggunakan maka caregiver akan semakin mengetahui detail dan dapat mengoptimalkan penggunaan dukungan visual.

Saran untuk peneliti selanjutnya yaitu melihat bagaimana topik ini masih jarang diteliti untuk itu literatur yang dipakai masih belum maksimal. Penulis yakin masih ada sumber yang lebih baik lagi. Diharapkan peneliti selanjutnya dapat mendapatkan teori dan sumber bacaan yang lebih baik. Saat penelitian ini dilakukan salah satu subjek sudah banyak melupakan pengalamannya karena kejadian yang berkaitan terjadi di masa lalu, peneliti selanjutnya diharapkan dapat menemukan subjek yang masih banyak mengingat.

\section{U C A P A N T E R I MAKASIH}

Penulis ingin mengungkapkan terima kasihnya kepada seluruh pihak yang telah berjasa dalam penelitian ini, Bu Rini selaku dosen pembimbing penulis yang selalu sabar dan bersedia dalam membimbing penulis. Partisipan dalam penilitian ini yaitu AS dan RH yang dengan besar hati telah menyediakan waktunya untuk penulis serta berbagi pengalaman dan ilmu yang dimiliki. Serta Fakultas Psikologi UNAIR tempat dimana penulis menuntut ilmu.

\section{DEKLARASI POTENSI TERJADINYA KONFLIK KEPENTINGAN}

Hanun Nurfadiyah dan Tri Kurniati Ambarini tidak bekerja, menjadi konsultan, memiliki saham, atau menerima dana dari perusahaan atau organisasi manapun yang mungkin akan mengambil untung dari diterbitkannya naskah ini. 


\section{PUST AKA ACUAN}

American Psychiatric Association. (2013). Diagnostic and Statistical Manual of Mental Disorder Fifth Edition. Arlington, VA: American Psychiatric Association.

Braun, V., \& Clarke, V. (2006). Using Thematic Analysis in Psychology. Qualitative Research in Psychology, $2-41$.

Dettmer, S., Simpson, R. L., Myles, B. S., \& Ganz, J. B. (2000). The use of visual supports to facilitate transitions of students with autism. Focus on autism and other developmental disabilities, 163169.

Dyrbjerg, P., \& Vedel, M. (2007). Everyday Education Visual Support for Children with Autism. London: Jessica Kingsley Publishers.

Ginanjar, A. S. (2007). Memahami spektrum autistik secara holistik. Makara, Sosial Humaniora, vol 11, no. 2, 87-99.

Grandin, T. (1995). Thinking in pictures: And other reports from my life with autism. New York: Doubleday.

Hayes, G. R., Hirano, S., Marcu, G., Monibi, M., Nguyen, D. H., \& Yeganyan, M. (2010). Interactive visual supports for children with autism. Pers Ubiquit Comput, 663-680.

Hill, E. (2004). Evaluating the theory of executive dysfunction in autism. Developmental Review, 24, 189233.

Hume, K., Wong, C., Plavnick, J., \& Schultz, T. (2014). Use of Visual Supports with Young Children with Autism Spectrum Disorder. In J. Tarbox, D. R. Dixon, P. Strumey, \& J. L. Matson, Handbook of Early Intervention for Autism Spectrum Disorder (pp. 375-402). New York: Springer Science+Business Media.

Hunt, C. K. (2003). Concept in Caregiver Research. Journal of Nursing Scholarship, 27-31.

Iowa Departement of education early childhood services beurau. (2010). Talking to parents about autism. Iowa: Iowa Departement of education early childhood services beurau.

Johnston, S., Nelson, C., Evans, J., \& Palazolo, K. (2003). The use of visual supports in teaching young children with autism spectrum disorder to initiate interactions. Augmentative and alternative communication 19 (2), 86-103.

KBBI. (n.d.). Pengasuh. Retrieved April 4, 2020, from KBBI Daring: https://kbbi.kemdikbud.go.id/entri/pengasuh

Koesdiningsih, T. (2018). Pengaruh penggunaan visual support terhadap perbaikan klinis anak dengan autism spectrum disorder (ASD) di unit pelayanan terpadu daerah anak berkebutuhan khusus (UPTD ABK) Sidoarjo. Surabaya: IR-PERPUSTAKAAN UNIVERSITAS AIRLANGGA.

Kunda, M., \& Goel, A. K. (2011). Thinking in pictures as a cognitive account of autism. Journal of Autism and Developmental Disorder, 41, 1157-1177. 
McLeod, S. A. (2012). Working Memory. Retrieved Maret 01, 2020, from Simply Psychology: https://www.simplypsychology.org/working\%20memory.html

Meadan, H., Otrosky, M. M., Triplett, B., Michna, A., \& Fettig, A. (2011). Using VIsual Support With Young Children With Autism Spectrum Disorder. Teaching exceptional young children. Vol 43, No 6, 2835.

Milligan, C. (2005). From home to 'home': situating emotions within the caregiving experience. Environment and Planning A 2005, volume 37, 2105-2120.

Ratri, D. (2016). Buku Psikologi ABK. Yogyakarta: Psikoasain.

Siller, M., \& Sigman, M. (2002). The Behaviors of Parents of Children with Autism Predict the Subsequent Development of Their Children's Communication. Journal of Autism and Developmental Disorders, Vol. 32, No. 2, 77-89.

Tager-Flusberg, H. (2003). Language impairments in children with complex neurodevelopmental disorder. Languange competence across population, 297-321.

Tager-Flusberg, H., Paul, Rhea, \& Lord, C. (2019). Language and communication in autism. In H. TagerFlusberg, Paul, Rhea, \& C. Lord, Development and behaviour (pp. 89-111). Cambridge University Press. 